\title{
POTENTIAL INEQUALITY REVISITED I: GENERAL CASE
}

\author{
Neven Elezović, Josip PeČarić And MarJan PraljaK
}

Abstract. The main subject of this paper is a detailed study of potential inequality, which was introduced in [5]. Original inequality is extended to the case of general convex and concave functions. Various functionals connected with this inequality are defined and some improvements or refinements of known inequalities are given. Special attention is given to exponential convexity of such functionals. The inequalities obtained here are of general nature. They will be specified and studied in more details with concrete examples of involved kernels in our forthcoming papers.

Mathematics subject classification (2010): 26D15.

Keywords and phrases: Potential inequality, convex function, exponential convexity.

\section{REFERENCES}

[1] M. Anwar, J. JakšEtić, J. PeČArić, AtiQ Ur Rehman, Exponential convexity, positive semidefinite matrices and fundamental inequalities, J. Math. Inequal. 4 (2010) 171-189.

[2] A. Kufner, H. Triebel, Generalization of Hardy's inequality, Confer. Sem. Mat. Univ. Bari 156 (1978), 1-21.

[3] J. Pečarić, F. Proschan, Y. C. Tong, Convex Functions, Partial Orderings and Statistical Application, Academic Press, San Diego, 1992.

[4] M. RAO, Brownian Motion and Classical Potential Theory, Lecture Notes Series No. 47, Aarhus University, 1977.

[5] M. RAO, H. ŠIKIĆ, Potential Inequality, Israel J. Math. 83 (1993), 97-127. 